BoL. Soc. Bot. MÉxico 33:13-30, 4 figs. (1974.)

\title{
LOS REGISTROS MAS ANTIGUOS DEL POLEN DE NOTHOFAGUS (Fagaceae) DE PATAGONIA (ARGENTINA Y CHILE)
}

\author{
por Sergio Archangelsky* y Edgardo Romero**
}

\section{INTRODUCCION}

El objeto del presente trabajo es presentar las evidencias más antiguas del género Nothofagidites conocidas hasta hoy para América del Sur.

El género Nothofagus es actualmente el más importante de los que habitan los Bosques Subantárticos de Patagonia. Por ello nos pareció adecuado profundizar el estudio de sus granos de polen dispersos (organogénero Nothofagidites), pues el conocimiento de su historia revela en gran parte la historia del mismo bosque y de los cambios acaecidos en el ambiente de su desarrollo.

Los antecedentes en este sentido son escasos. Cookson y Cranwell (1967) estudiaron sedimentos de la Formación Leña Dura (Eoceno superior), cerca de Punta Arenas, Chile, hallando pocos granos de Nothofagidites de los tipos fusca y brassi, mal preservados, que distinguieron por números. En la misma región Fasola (1969) investigó los sedimentos de la Formación Loreto (Eoceno superior-Oligoceno inferior) ; encontró 4 especies ( $N$. cinota, $N$. cf. waipawensis, $N$. cf. cranwellae, $N$. sp.), correspondientes a los tres tipos de granos de polen de este género. En esta formación la importancia del género es manifiesta dado que en algunos niveles domina el espectro polínico. Hasta donde conocemos, no se ha realizado otro estudio sobre el tema para el lapso Cretácico superior-Terciario inferior.

Las muestras estudiadas fueron obtenidas de distintas maneras. Algunas han sido donadas por colegas que estudiaron su contenido micropaleontológico. A ello agradecemos su colaboración: Dr. R. Charrier, Universidad de Santiago, Chile y Dra. A. Bertels, Universidad de Buenos Aires, Argentina. Otras fueron coleccionadas por los autores en varias expediciones realizadas a la Provincia de Chubut como parte del Plan Terciario que se desarrolla con un subsidio del

* Profesor Titular y Jefe de División Paleobotánica, Facultad de Ciencias Naturales y Museo, Universidad Nacional de La Plata. Miembro de la Carrera del Investigador, Consejo Nacional de Investigaciones Científicas y Técnicas de Buenos Aires, Argentina.

* * Departamento de Biología, Facultad de Ciencias Exactas y Naturales, Universidad Nacional de Buenos Aires. 
Consejo Nacional de Investigaciones Científicas. Por último, otras fueron coleccionados también por los autores, junto con el Lic. J. C. Gamerro (Universidad Nacional de La Plata), en un viaje realizado a Río Turbio, Provincia de Santa Cruz (Argentina).

El trabajo consta de una parte principal (presentación del material, ubicación estratigráfica y datos sobre paleoambientes). Luego se desarrollan las conclusiones paleoecológicas y estratigráficas que surgen del presente estudio. No se ha intentado realizar un trabajo sistemático riguroso con las especies, puesto que el mismo se halla en preparación por uno de los autores (E. J. R.). Sólo se caracterizan e ilustran someramente las especies más importantes.

\section{Material estudiado}

En el presente capítulo se mencionan todas las especies de Nothofagidites que se han reconocido en las diferentes unidades litoestratigráficas de Patagonia, las que cronológicamente abarcan el lapso Maastrichtiano medio-Eoceno medio. En cada sección se vierten primero los datos estratigráficos disponibles, con las fuentes que permiten la datación; luego se caracterizan las especies de Nothofagidites y finalmente se incluyen las referencias sobre las condiciones ambientales que surgen de la literatura consultada.

1.-Formación Jagüel, Fortín General Roca, Provincia de Río Negro.

Una muestra de superficie ha brindado material palinológico. Fue cedida por la Dra. A. Bertels y lleva la sigla NCW7. La procedencia geográfica de la misma está indicada en Bertels (1969 fig. 1 p. 47) y la ubicación estratigráfica está dada en el mismo trabajo (fig. 2, columna izquierda). Dicha muestra, de acuerdo al control micropaleontológico (Bertels 1. c.) está datada en el Maastrichtiano medio (Cretácico superior), y la unidad litoestratigráfica correspondiente es la Formación Jagüel.

Las especies de Nothofagidites presentes son dos:

a) Nothofagidites aspera Cookson 1958 (Lám. 1 fig. 1). Se han hallado sólo 2 granos con exina bien conservada. Uno presenta las típicas aberturas desgarradas, pero el otro las tiene aún sin abrir. Heusser (1971) ha mostrado que esto último ocurre frecuentemente en Nothofagus glauca (Phil.) Krasser. El diámetro de ambos granos es similar al de los más pequeños de la descripción original, y los demás caracteres coinciden perfectamente. $N$. aspera ha sido citada para el Maastrichtiano-actual de Nueva Zelandia (Couper 1960), EoPlioceno de Australia (Cookson 1958) y Eo-Oligoceno de Punta Arenas, Chile (Fasola 1969). 
b) Nothofagidites sp. 1 (Lám. 1. fig. 2). Se trata de granos más abundantes oue los anteriores, del tipo fusca, medianos a grandes, con 5-7 colpos (principalmente 6), de forma subpoligonal a redondeada en vista polar. Las espinas son débiles pero en algunos granos pueden verse al corte óptico con 700 aumentos. Las especies más similares serían $N$. brachispinulosa Cookson 1958 y $N$. cinctu Cookson 1958, ambos del Eoceno-Mioceno de Australia. Harris (1965) cita $N$. cf. brachispinulosa para el Paleoceno de Australia.

Condiciones ambientales.-De acuerdo a Volkheimer (1971) la presencia de grandes reptiles poiquilotermos indica que en el Senoniano el clima de Patagonia debió ser subtropical y húmedo; como el mismo régimen subsistió en el Paleoceno (ver más adelante), posiblemente en el Maastrichtiano medio esas eran las condiciones. La presencia de árboles petrificados en algunos sedimentos del Cretácico superior, indica la existencia de comunidades boscosas, aunque en menor grado que durante el Paleoceno.

2.-Formación Cerro Dorotea, Provincia de Santa Cruz.

Diferentes muestras de superficie y subsuelo han brindado ricas asociaciones polínicas. La Formación Cerro Dorotea integra una espesa pila sedimentaria que principia en la base con la Formación Cerro Cazador, portadora de ammonites que indican una antigüedad maastrichtiana inferior (Hünicken, 1965); en aparente concordancia siguen las capas de la Formación Cerro Dorotea, que incluyen dos horizontes de carbón. La palinología del horizonte inferior, recientemente desarrollada por Freile (1971) no permitió definir con precisión la antigüedad de esta sección; la misma estaría unicada en el lapso Maastrichtiano. Paleoceno. El material con Nothofagidites procede de la parte alta de esta formación (horizonte carbonoso superior) y la misma podría asignarse tentativamente al Paleoceno inferior. El techo de esta formación está en contacto discordante con la Formación Río Turbio, datada en el Eoceno inferior a medio (ver más adelante).

El género Nothofagidites se halla representado por tres especies, una de las cuales es de asignación dudosa. Ellas son:

a) Nothofagidites kaitangata Te Punga 1948 (Lám. 1 fig. 4). Granos chicos, con 6-7 colpos, sin engrosamientos pero claramente delimitados por un reborde brillante del mismo espesor que la exina. Las espinas son medianas (sólo en unos pocos granos no se ven al corte óptico) y de amplia base, probablemente igual que la altura. Pertenece al tipo brassi y es relativamente abundante. El material sudamericano es muy similar a la descripción original, variando ligeramente en el diámetro ecuatorial y el número y profundidad de los colpos. La espina de base ancha que al corte óptico aparece aproximadamente como 
un triángulo equilátero, es un carácter que facilita la determinación. Cabe destacar que en la descripción original Te Punga no cita engrosamientos en los colpos. Sin embargo Couper $(1953,1960)$ estudiando material del yacimiento tipo, describe e ilustra para esta especie un engrosamiento como el citado más arriba. $N$. kaitangata ha sido descripta para el Senoniano-Maastrichtiano de Nueva Zelandia.

b) Nothofagidites sp. 2 (Lám. 1 fig. 5). Granos relativamente abundantes, medianos, poligonales en vista polar, con 6-8 colpos claramente limitados por un reborde brillante del mismo espesor que la exina, de espinas finas y delicadas (aunque suelen verse al corte óptico). Pertenecen al grupo brassi y son menos frecuentes que la especie anterior. La especie más similar sería $N$. kaitangata, aunque difiere en el diámetro ecuatorial, en el número y profundidad de los colpos y en la naturaleza y densidad de las espinas. $N$. senectus Dettmann y Playford 1958 del Senoniano de Australia, se asemeja en algunos caracteres, pero difiere en el diámetro, el número y profundiad de los colpos y la densidad y naturaleza de las espinas. $N$. sp. 6 , descripta más abajo, es tal vez más similar, pero puede distinguirse por el mayor diámetro ecuatorial, la forma en vista polar - que puede ser redondeada-y el número de colpos que es más variable.

c) Nothofagidites cf. waipawensis Couper 1960 (Lám. 1 fig. 6). Granos más escasos que los anteriores citados en este yacimiento, chicos, poligonales en vista polar, con 6.7 colpos ligeramente engrosados (hasta 2 veces el espesor de la exina) de espinas fuertes y subfuertes. El material observado coincide con la descripción original en una serie de caracteres, pero difiere en la forma, número de colpos y en que algunos ejemplares tienen espinas subfuertes. Lo mismo ocurre en relación a los granos descriptos por Fasola (1969) de esta especie. Por ello, la asignación específica se mantiene en reserva. Couper describió la especie para el Daniano de Nueva Zelandia y Fasola para el Eo-Oligoceno de Loreto (Chile).

Condiciones ambientales.-La asociación polínica presenta muy pocos ejemplares de Nothofagidites y de Gimnospermas; además, se han observado muchos ejemplares idénticos a la asociación polínica del Salamanquense. Ello, parece indicar un régimen climático cálido a templado-cálido y húmedo (carbón). Comparativamente, el régimen es más cálido que durante el Eoceno (ver más adelante) y más aún que en la actualidad.

3.-Formación Río Blanco, Chile Austral.

Las muestras con material polínico proceden de la parte superior de la Formación Río Blanco, en la costa oeste del Estrecho de Magallanes. De acuerdo a Charrier y Lahsen $(1968,1969)$ la presencia de especies características de 
foraminiferos y ammonites, indica una antigüedad maastrichtiana superior a media.

Sólo se hallaron 6 granos de Nothofagidites, correspondientes a $N$. kaitan. gata (Lám. 1 fig. 3). Sin embargo, cabe señalar que el escaso material responde mejor a la descripción original que el de la Formación Cerro Dorotea. Esto es válido especialmente para el número de colpos (algunos con 5) y en su pro. fundidad.

No poseemos datos sobre las condiciones ambientales imperantes en la época de la depositación de estos sedimentos.

4.--Formación Salamanca y Formación Bororó, Provincia de Chubut.

Las muestras que brindaron polen corresponden a perfiles de superficie de dos unidades litoestratigráficas. La primera, Formación Salamanca, aflorante y en subsuelo de la Cuenca del Golfo San Jorge. En uno de los perfiles más completos, en el área típica (Bajada de Hansen) existe un control micropaleontológico (Bertels, comunicación verbal) que indica una antigüedad daniana de estas capas. Estos datos están de acuerdo con los estudios micropaleontológicos de Méndez (1966) realizados sobre un perfil de la misma secuencia algo más al sur (Punta Peligro). La segunda unidad litoestratigráfica que brindó restos de polen es la Formación Bororó, en el río Chubut Medio (Andreis et. al. 1972). También existe un control micropaleontológico de esta unidad (Bertels 1972), que indica una antigüedad daniana de las capas, y por lo tanto éstas son sincrónicas con las de Hansen.

El género Notofagidites se halla muy pobremente representado por ejemplares aislados de asignación dudosa. En el perfil de Hansen, al cabo de una ex. haustiva búsqueda en varios niveles, se hallaron 4 granos correspondientes al tipo brassi (Lám. 1 fig. 8). Son similares a los de Nothofagidites sp. 3, que serán tratados en más detalle en el capítulo siguiente (Formación Río Chico). En los perfiles del Cerro Bororó se hallaron otros 3 granos, pero del tipo fusca (Lám. 1 fig. 7). Son idénticos a otros granos que se describen en el título siguiente.

Condiciones ambientales. Pascual y Odreman Rivas (1971) en base a la presencia de algunos grupos de reptiles, concluyen que el clima en esta región patagónica - por lo menos hasta la parte media de la superficie actual- fue lo suficientemente cálido y con precipitaciones pluviales como para permitir la vida de reptiles tan particulares como los Crocodilia. La presencia, en estos mismos sedimentos de petrificaciones de palmeras y otras angiospermas (Petriella 1972), indican las mismas condiciones mesológicas válidas para la parte central de la Patagonia argentina. 


\section{5) Formación Río Chico, Provincia de Chubut.}

Dos muestras de superficie han brindado material palinológico. Fueron coleccionadas en el perfil de Puerto Visser, al norte de Comodoro Rivadavia, en la Provincia de Chubut. La sección sedimentaria de esta unidad apoya sobre términos marinos y costaneros de la Formación Salamanca y es netamente con. tinental. Esta unidad, aflora ampliamente en toda la zona y es conocida por la presencia de buenos restos de vertebrados fósiles. Dichas faunas indican una antigüedad paleocena superior (Thanetiano) y corresponden a la Edad Riochiquense (Pascual et al. 1965).

Como hemos señalado más arriba, aparecen en esta formación granos de Nothofagidites de los tipso fusca y brassi. Ellos son:

a) Nothofagidites sp. 3 (Lám. 1 fig. 9). Granos de polen del tipo brassi, relativamente abundantes, chicos y poligonales, con 6-8 colpos (en general 7). Colpos con un reborde del mismo espesor que la exina o ligeramente superior. Espinas fuertes, en algunos casos más grandes y espaciadas en los polos. La especie más similar sería $N$. deminuta Cookson, de la que difiere algo en el diámetro, la profundidad de los colpos y la densidad de espinas. $N$. emarcida Cookson tiene también algunos rasgos en común pero difiere por la forma en vista polar, el número y profundidad de los colpos y el espesor de la exina. Ambas especies fueron descritas para el Eoceno-Mioceno de Australia y Harris (1965) cita a la segunda para el Daniano del mismo continente.

b) Nothofagidites cf. brachispinulosa Cookson 1958 (Lám. 1 fig. 10). Muy pocos granos, algo alterados, medianos, redondeados en vista polar, con 5-6 colpos engrosados y espinas muy débiles. El material difiere del original en varios caracteres (número de colpos, espesor de la exina) y tal vez corresponde a otra especie; sin embargo, ante la falta de suficientes especímenes se ha preferido asignarlos provisoriamente a la especie de Cookson. N. brachispinulosa fue descripta para el Eoceno-Mioceno de Australia y Harris (1965) la cita para el Paleoceno del mismo continente.

Condiciones ambientales.-Pascual y Odreman Rivas (1971) señalan que durante la Edad Riochiquense el territorio de la parte central de Patagonia debió ser relativamente llano, con un clima subtropical a templado cálido; la vegetación, en una región de sabanas, era arbustiva con manchones de vegetación arbórea (hay presencia de numerosos troncos petrificados en diversas localidades). Las precipitaciones pluviales debieron ser relativamente abundantes.

6. Formación Río Turbio, Provincia Santa Cruz.

El material que se cita proviene de numerosas muestras de superficie y 
subsuelo. La Formación Rio Turbio ha sido datada últimamente en el Eoceno medio (quizás inferior alto) en base al contenido de microplancton (Archangelsky 1969). La presencia de Venericardia grupo planicosta, confirma una antigüedad eocena, y de acuerdo a las últimas conclusiones (Camacho, comunicación verbal) correspondería a un Eoceno inferior.

Hemos tenido también en cuenta las referencias sobre la presencia del género en capas de antigüedad muy similar o próxima en el área austral de Chile (Cookson y Cranwell, 1967; Fasola, 1969).

Las especies de Nothofagidites presentes son numerosas y variadas, y ello ha permitido agruparlas de acuerdo al tipo de grano de polen: menziesi, fusca o brassi. Cabe señalar que la lista de especies que se reseña a continuación no es exhaustiva, ya que se presentan otros tipos más, pobremente representados.

a) Especies del grupo menziesi.

Nothofagidites aspera Cookson 1958 (Lám. 2 fig. 1). Granos escasos, poligonales en vista polar, medianos a grandes, con 6-7 aperturas colpoidales que semejan rupturas de la exina. Espinas fuertes. Se hallaron pocos ejemplares, lo que explicaría que la variación de los caracteres cuantitativos se produce en un rango menor que en la descripción original. Fasola (1969) describió como Nothofagidites sp. granos idénticos a estos, también muy escasos. El material original corresponde a capas del Eoceno-Plioceno de Australia, mientras que el de Chile al Eoceno-Oligoceno de Punta Arenas. Como ya se indicó, Couper (1953, 1960) la ha citado para el Maastrichtiano-actual de Nueva Zelandia.

Nothofagidites sp. 4. (Lám. 2 fig. 2). Granos escasos, poligonales en vista polar, con 4-7 aperturas colpoidales medianas a profundas. Espinas fuertes. Difiere de la especie anterior por el diámetro ecuatorial y la menor densidad de espinas. De las otras especies del grupo menziesi difiere además en otros caracteres.

b) Especies del grupo fusca.

Nothofagidites cincta Cookson 1958 (Lám. 2 fig. 3). Granos medianos a grandes, abundantes, poligonales en vista polar, con 6-8 colpos engrosados y espinas débiles. El material americano difiere del original por tener colpos menos engrosados y diámetro menor. Cookson describió la especie para el Eoceno-Mioceno de Australia.

Nothofagidites brachispinulosa Cookson 1958 (Lám. 2 fig. 4). Granos pequeños, poligonales en vista polar (aunque hay algunos redondeados), con 6-8 colpos engrosados y relativamente profundos, y espinas débiles. Es muy similar al material original, del que difiere ligeramente por el número de colpos y tal vez por la forma, que es más frecuentemente redondeada en los ejemplares australianos. 
Nothofagidites sp. 5 (Lám. 2 fig. 5). Granos pequeños, generalmente redondeados en vista polar, con 5-8 colpos engrosados y con espinas débiles. La especie más similar sería $N$. brachispinulosa de la que difiere por el diámetro ecuatorial, los colpos más engrosados y la mayor densidad de espinas. La variación más grande está sin embargo en la forma en vista polar, ya que son raros los granos poligonales.

c) Especies del tipo brassi.

Nothofagidites deminuta Cookson 1958 (Lám. 2 fig. 6). Granos pequeños, redondeados o poligonales en vista polar, con 5-7 colpos que tienen un leve engrosamiento, o bien éste falta. Espinas fuertes, a veces más grandes en los polos. Fue citada para el Eoceno-Oligoceno de Australia.

Nothofagidites cranwellae Couper 1953 (Lám. 2 fig. 7). Granos pequeños, generalmente poligonales en vista polar, con 4-7 colpos, a veces con tenue engrosamiento. Espinas débiles. El material americano es muy similar al original, salvo en la densidad de espinas y el diámetro ecuatorial, que varía en rangos mayores. La coincidencia con los ejemplares descriptos por Fasola (1969), en cambio, es casi perfecta. Couper describió la especie para el Mioceno-Pleistoceno de Nueva Zelandia, y le sinonimizó luego, en 1960, N. tepungai Couper 1953, del Oligoceno-Mioceno del mismo país. El material de Fasola es Eoceno-Oligoceno.

Nothofagidites sp. 6 (Lám. 2 fig. 8). Granos abundantes, medianos, poligonales en vista polar, con 5-9 colpos rodeados por un delgado margo de igual espesor que la exina. Esta es relativamente gruesa y está cubierta por espinas débiles. Entre el material fósil descripto en la literatura no hay especies similares a ésta. Las menos distintas serían $N$. incrassata y $N$. goniata descriptas por Cookson (1958) para el Eoceno y el Terciario inferior, respectivamente, de Australia. Ambas difieren mucho de nuestro material en caracteres importantes, tales como la forma en vista polar, el tipo de espinas, etc.

Condiciones ambientales.-Para el Sur de Patagonia, el clima era templado, como lo atestiguan las numerosas especies de esporas (Archangelsky, 1972), la presencia de muchas capas e hiladas de carbón, etc. Volkheimer (1971) indica que hubo mayor humedad que en el Paleoceno u Oligoceno, y que el clima fue más cálido que en la actualidad. Más hacia el norte, de acuerdo a los restos de vertebrados fósiles (Pascual et al. 1965), en sedimentos posiblemente coetáneos (Mustersense) se registra un significativo cambio climático, que consiste en una atemperación, producida luego de un ascenso epirogenético de la parte central de Patagonia. Finalmente, en el área del Turbio, las asociaciones palinológicas difieren marcadamente de las infraestantes (Formación Cerro 
Dorotea), estas últimas con numerosas especies comunes al Salamanquense. Este cambio, también indicaría una marcada atemperación del clima.

\section{CONCLUSIONES PALEOECOLOGICAS}

De acuerdo a la información que poseemos sobre las condiciones ambientales, durante el Cretácico superior y el Terciario inferior (Daniano), en Patagonia ha prevalecido un clima esencialmente cálido y húmedo (subtropical a francamente tropical).

La evidencia palinológica basada en el género Nothofagidites permite efectuar las siguientes observaciones.

1. En todos los yacimientos cretácicos y danianos estudiados, el porcentaje de Nothofagidites en las asociaciones polínicas es muy bajo (del orden 1-3\%). Considerando la antigüedad de las capas podemos señalar que en los sedimentos más antiguos (Formación Jagüel, Fm. Dorotea, Chile) hay una mayor frecuencia y un mayor número de especies; en cambio, en sedimentos salamanquenses, el porcentaje y la variedad específica son mínimas (incluso en algunos perfiles que no se han considerado, no se han hallado evidencias). Quizás esto puede indicar que dentro de las condiciones ecológicas ya señaladas para este lapso, durante el tiempo Salamanquense las mismas alcanzaron una óptima expresión con un régimen de extrema humedad y temperatura.

2. En el área norte (Fm. Jagüel) se ha encontrado una especie del grupo menziesi (N. aspera); actualmente en Patagonia existen 3 especies de Nothofagus (N. oblicua, N. glauca y $N$. procera) cuyos granos de polen corresponden al mismo grupo. Ellas viven en el extremo septentrional del área de distribución del género, allí donde las condiciones ambientales son menos rigurosas.

3. En el área sur (Chile y Fm. Cerro Dorotea) y central (Formaciones Salamanca y Bororó) las especies dominantes de Nothofagidites son del grupo brassi, el que actualmente se halla restringido a Nueva Guinea, Nueva Caledonia (y posiblemente a Chile, con $N$. alessandri). En estas áreas las condiciones mesológicas son húmedas y templado a cálidas (siendo las más benignas del área de distribución actual del género).

En cuanto a la distribución geográfica de las especies reconocidas en el lapso Cretácico superior-Daniano, surgen evidencias que permiten diferenciar las áreas norte de las áreas centro y sur. Las especies del grupo menziesi serían exclusivas del área norte, mientras que las del grupo brassi se hallarían en el centro y sur. Las del grupo fusca están presentes en toda la Patagonia, 
pero $N$. sp. 1 (del área norte) es formológicamente muy diferente a $N$. cf. brachispinulosa y $N$. cf. waipawensis (de las áreas centro y sur). Estas últimas son bastante parecidas entre sí.

En el Paleoceno superior sólo tenemos información del área central patagónica (Riochiquense). Las asociaciones polínicas presentan un mayor porcentaje de Nothofagidites (hasta 9\%). Ello estaría de acuerdo con las condiciones ambientales que se han establecido para el área: régimen climático húmedo pero más templado que en la época salamanquense.

Las dos especies reconocidas son las mismas que se han citado para el Salamanquense. Parecería entonces que las especies de Nothofagidites dentro de un mismo ámbito geográfico (y posiblemente también fisiográfico) pueden persistir a través del tiempo y aumentar su frecuencia con un cambio favorable del régimen climático. Para este género, la atemperación del clima parece corresponder a un mejoramiento mesológico.

En el Eoceno (inferior a medio) tenemos información sólo para el área austral de Patagonia. Se produce un desarrollo casi explosivo de Nothofagidites que en las asociaciones alcanza una representación de hasta 30\%; al mismo tiempo, el número de especies se eleva a más de 8 , pertenecientes a los tres tipos de granos que se reconocen en el género. Algunas especies son morfológicamente similares a las halladas en el Riochiquense ( $N$. brachispinulosa, $N$. deminuta). Esto indicaría la existencia de condiciones mucho más favorables para el desarrollo del género y coincidiría con las conclusiones que se han esbozado para la época en que se depositó la Fm. Río Turbio, que relativas al clima indican templado y húmedo. El elevado número de especies estaría indicando la existencia de distintos nichos ecológicos, posiblemente debidos a una fisiografía variada que fue el resultado de los movimientos que comenzaron a modelar la cadena andina. Podemos inferir las mismas condiciones ambientales y composición florística para esta área a través del Eoceno superior y Oligoceno inferior, de acuerdo a la información palinológica sobre la Formación Loreto (Chile Austral, Fasola 1969).

\section{CONCLUUSIONES ESTRATIGRAFICAS}

El género Nothofagidites se registra por primera vez en el Cretácico. En el Senoniano aparece una especie en Australia y otra en Nueva Zelandia, ambas del grupo brassi; durante el Maastrichtiano se agrega en Nueva Zelandia una nueva especie, $N$. aspera, del grupo menziesi, y en Australia el género no se ha registrado aún. Esto contrasta con lo que ocurre en América del Sur: aquí 
ya en el Maastrichtiano medio tenemos la presencia de 3 especies pertenecientes a los tres grupos del género. En efecto, el grupo fusca se hace presente en Nueva Zelandia y Australia recién en el Daniano ( $N$. waipawensis y $N$. cf. brachispinulosa, respectivamente). En América del Sur, en cambio, N. sp. 1 aparece ya en los sedimentos de la Formación Jagüel. Durante el Maastrichtiano en América del Sur - al igual que en otros continentes - el género es poco importante aún, pero la variedad de especies y la distancia entre los yacimientos portadores (Roca se halla a unos $1,500 \mathrm{~km}$. de la localidad chilena) indican que ha tenido en nuestro continente una larga historia previa. En este sentido debemos señalar que los sedimentos más antiguos del Cretácico superior (Senoniano, Turoniano) no han sido estudiados aún desde el punto de vista palinológico y por lo tanto no debe descartarse la posibilidad de hallar en ellos granos de Nothofagidites, especialmente si la búsqueda se orienta atendiendo a las nuevas evidencias paleoecológicas que van surgiendo para $\mathrm{Pa}$. tagonia.

Durante el Paleoceno las especies son escasas en los otros continentes, y lo mismo ocurre en América del Sur. Sin embargo, aquí la frecuencia de individuos sufre una disminución marcada, cosa que no ocurre en Australia y Nueva Zelandia.

Por último, durante el Eoceno se produce un desarrollo explosivo del género que pasa a dominar las asociaciones polínicas con un elevado número de especies. El proceso es más o menos simultáneo y de iguales características en Australia y Nueva Zelandia. Durante el Eoceno, en las tres áreas, las especies pertenecen principalmente al grupo brassi (actualmente muy restringido) y al fusca. El grupo menziesi está pobremente representado, tanto por el número de especies como de ejemplares. Algunas especies de Nothofagidites son endémicas de las áreas mencionadas (durante el Eoceno); en nuestro continente hemos hallado 3 y las restantes parecen tener mayores relaciones con Australia que con Nueva Zelandia.

Las otras conclusiones estratigráficas surgen del análisis del Cuadro adjunto donde se han representado los biocrones conocidos de las especies determinadas, y los de las especies más afines a las nuevas. En general hay una gran coincidencia entre la evidencia palinológica y la de otro origen. Los casos que merecen destacarse son:

a) Parecen correctas las edades maastrichtiana de la Formación Río Blanco y Jagüel, daniana de la Fm. Salamanca, paleocena de la Fm. Río Chico y eocena de la Fm. Río Turbio.

b) La antigüedad de la Fm. Cerro Dorotea permanece incierta, ya que $N$. kaitangata indica afinidad con el Maastrichtiano mientras que $N$. cf. waipa- 


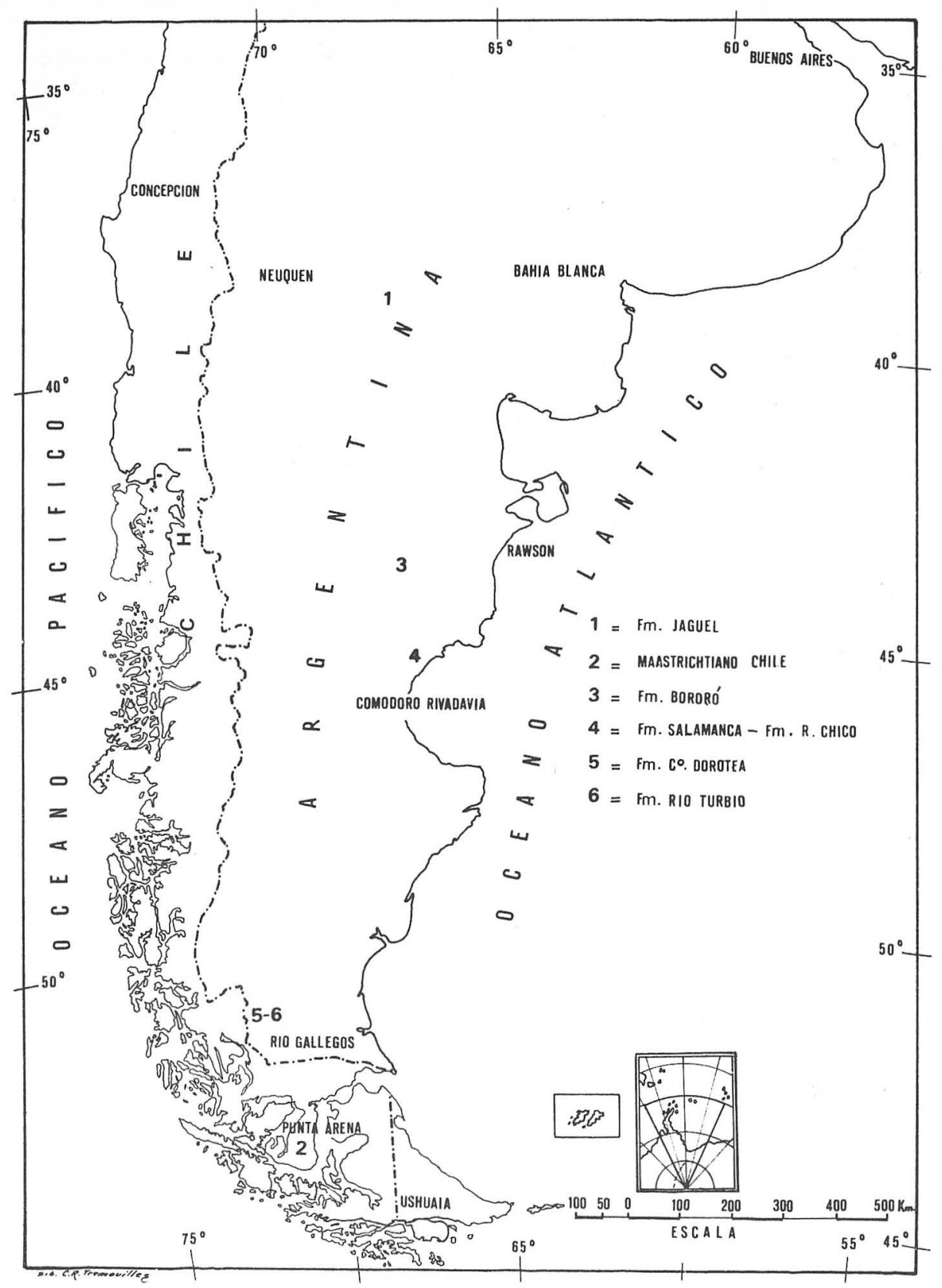




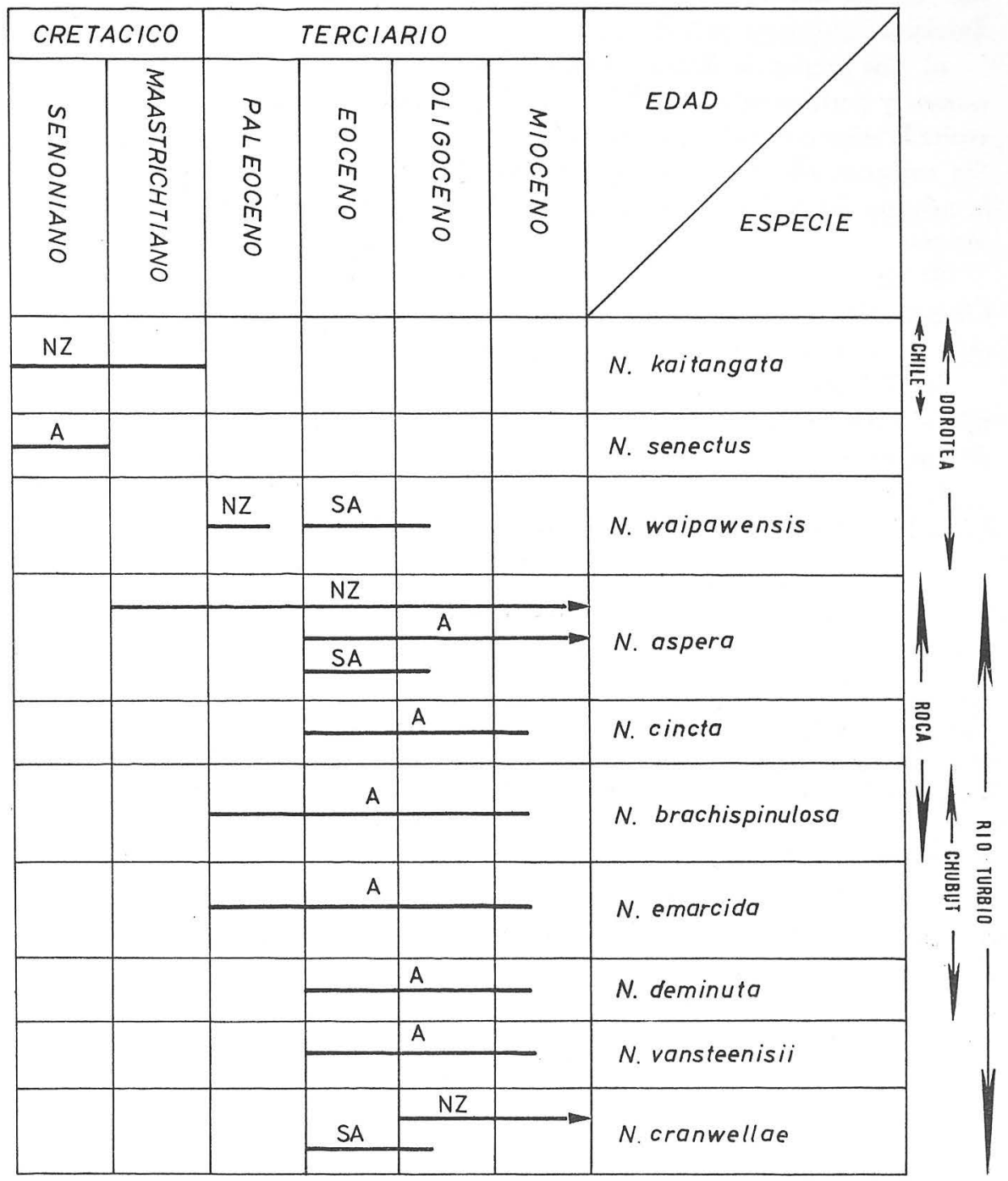


wensis parece señalar Daniano. De confirmarse esta última determinación, uno de los dos biocrones deberá extenderse cruzando el límite CretácicoTerciario.

c) Los granos de Nothofagidites de la Formación Río Blanco (Chile) son escasos y pertenecen a una única especie. En la Fm. Cerro Dorotea, donde se repite la misma especie, aparecen otras dos, y el género es algo más abundante. Sin embargo, ello no necesariamente indica una variación cronológica, ya que la primera formación es de facies de aguas profundas y la segunda de aguas someras.

d) La presencia de $N$. cf. brachispinulosa en los sedimentos paleocenos de Chubut (Formaciones Salamanca y Río Chico) confirma la extensión del biocrón de esa especie dada por Harris (1965).

e) El hallazgo de $N$. cf. waipawensis en la Formación Cerro Dorotea, amplía el biocrón sudamericano de la especie, en coincidencia con el hallazgo de Couper (1960) en Nueva Zelandia.

f) La presencia de $N$. cranwellae en el Eoceno de América del Sur, con. firma los datos de Fasola (1969), ampliando el biocrón de la especie.

\section{RESUMEN}

Se estudia la distribución y frecuencia de los granos de polen del organogénero Nothofagidites en sedimentos de distintas unidades litoestratigráficas de Patagonia. Se demuestra la presencia continua del género a partir del Maastrichtiano medio hasta el Eoceno. La frecuencia es muy baja en las formaciones cretácicas y danianas; aumenta en el Paleoceno superior y se hace significativa en el Eoceno. Se analizan los resultados en relación con las condiciones ambientales que han sido inferidas para este lapso en Patagonia. Finalmente se discuten los resultados estratigráficos, comparándolos con los registros conocidos para Australia y Nueva Zelandia.

\section{ABSTRACT}

The distribution and frequency of the pollen genus Nothofagidites in sediments of different lithostratigraphic units in Patagonia are studied. The genus has a continuous representation from Middle Maastrichtian to the Eocene. The frequency is low in Cretaceous and Danian formations, and it raises during the Upper Palaeocene becoming important in the Eocene. These results are 
analyzed in relation to the ecological conditions which have been inferred for this span of time in Patogonia. Finally, some stratigraphic conclusions are mentioned and they are related with the records already established for Australia and New Zealand.

\section{BIBLIOGRAFIA}

Andreis, R. R., Mazzoni, M. M. \& Spalletti, L. A. 1972. Geología y Sedimentología del Cerro Bororá, Provincia del Chubut (en prensa).

Archangelsky, S. 1969. Estudio del paleomicroplancton de la Formación Río Turbio (Eoceno) Provincia de Santa Cruz. Ameghiniana 6: 181-218.

1972. Esporas de la Formación Río Turbio (Eoceno) Provincia de Santa Cruz. Rev. Mus. La Plata n. s. Pal. 6, 65-100.

Bertels, A. 1969. Estratigrafía del límite Cretácico-Terciario en Patagonia septentrional. Rev. Asoc. Geol. Arg. 34, 41-54.

1972. Bioestratigrafía del Cerro Bororó, Provincia del Chubut, República Argentina (en prensa).

Cookson, I. 1958. Fossil pollen grains of Nothofagus from Australia. Proc. Roy. Soc. Victoria $71,25-30$.

. \& Cranwell, L. M. 1967. Lower Tertiary microplankton, spores and pollen grains from Southernmost Chile. Micropal. 13, 204-216.

Couper, R. A. 1953. Upper Mesozoic and Cainozoic spores and pollen grains from New Zealand. NZ Geol. Surv. Pal. Bull. 22.

1960. New Zealand Mesozoic and Cainozoic plant microfossils. N. Z. Geol. Surv. Pall. Bull 32.

Charrier, R. \& Lahsen A. 1968. Contribution a l'étude de la limite Cretacée-Tertiaire de la Province Magellan, extrème Sud du Chili. Rev. Micropa. 11, 111-120.

- _ \& 1 1969. Stratigraphy of Late Cretaceous-Early Eocene, Seno Skyring-Strait of Magellan Area, Magallanes Province, Chile. Amer. Ass. Petrl. Geol. 53, 568-590.

Dettmann, M. E.\& Playford, G. 1958. Taxonomy of some Cretaceous spores and pollen grains from Eastern Australia. Pr. Roy. Soc. Vict. 81, 69-94.

Fasola, A. 1969. Estudio palinológico de la Formación Loreto (Terciario medio) Provincia de Magallanes, Chile. Ameghiniana 6, 3-49.

Fraile, C. 1971. Estudio Palinológico de la Fm. Cerro Dorotea (Maastrichtiano-Paleoceno), Provincia de Santa Cruz. Rev. Mus. La Plata Pal. n. s. 6.

Harris, W. K. 1965. Basal Tertiary microfloras from the Princetown Area, Victoria, Australia. Palaeontographica $B$ 115, 75-106.

Heusser, C. A. 1971. Pollen and' Spores of Chile. Univ. Arizona Press, Tucson, U. S. A.

Hunicken, M. 1965. Algunos cefalópodos supracretácicos del Río Turbio Santa Cruz. Rev. Fac. Cs. Ex. Fís. Ns. Univ. Nac. Córdoba 26, 49-100.

Mendez, J. A. 1966. Foraminíferos, edad y correlación estratigráfica del Salamanquense de Punta Peligro, Provincia de Chubut. Rev. Asoc. Geol. Arg. 21, 127-157.

Pascual, R. \& al. 1965. Las edades del Cenozoico mamalífero de la Argentina, con especial atención a aquellas del territorio bonaerense. An Com. Inv. Cient. Bs. As. 6, 165-193.

Pascual, R. \& Odreman Rivas, O. E. 1971. Evolución de las comunidades de los Vertebrados del Terciario argentino. Los aspectos paleozoogeográficos y paleoclimáticos relacionados. Ameghiniana 7, 372-412.

Petriella, B. 1972. Estudio de las maderas petrificadas de la Formación Bororó (Paleoceno). Provincia de Chubut. Rev. Mus. La. Plata Pal. n. s. 6.

Te Punga, M. T. 1947. Nothofagus pollen from the Cretaceous coal measures at Kaitangata Otago, Nerw Zealand, N. Z. J. Sc. Techn. 829, 32-36.

Volkheimer, W. 1971. Aspectos paleoclimatológicos del Terciario Argentino. Rev. Mus. Arg. Cs. Ns. B. Rivadavia Pal. 1, 243-262. 

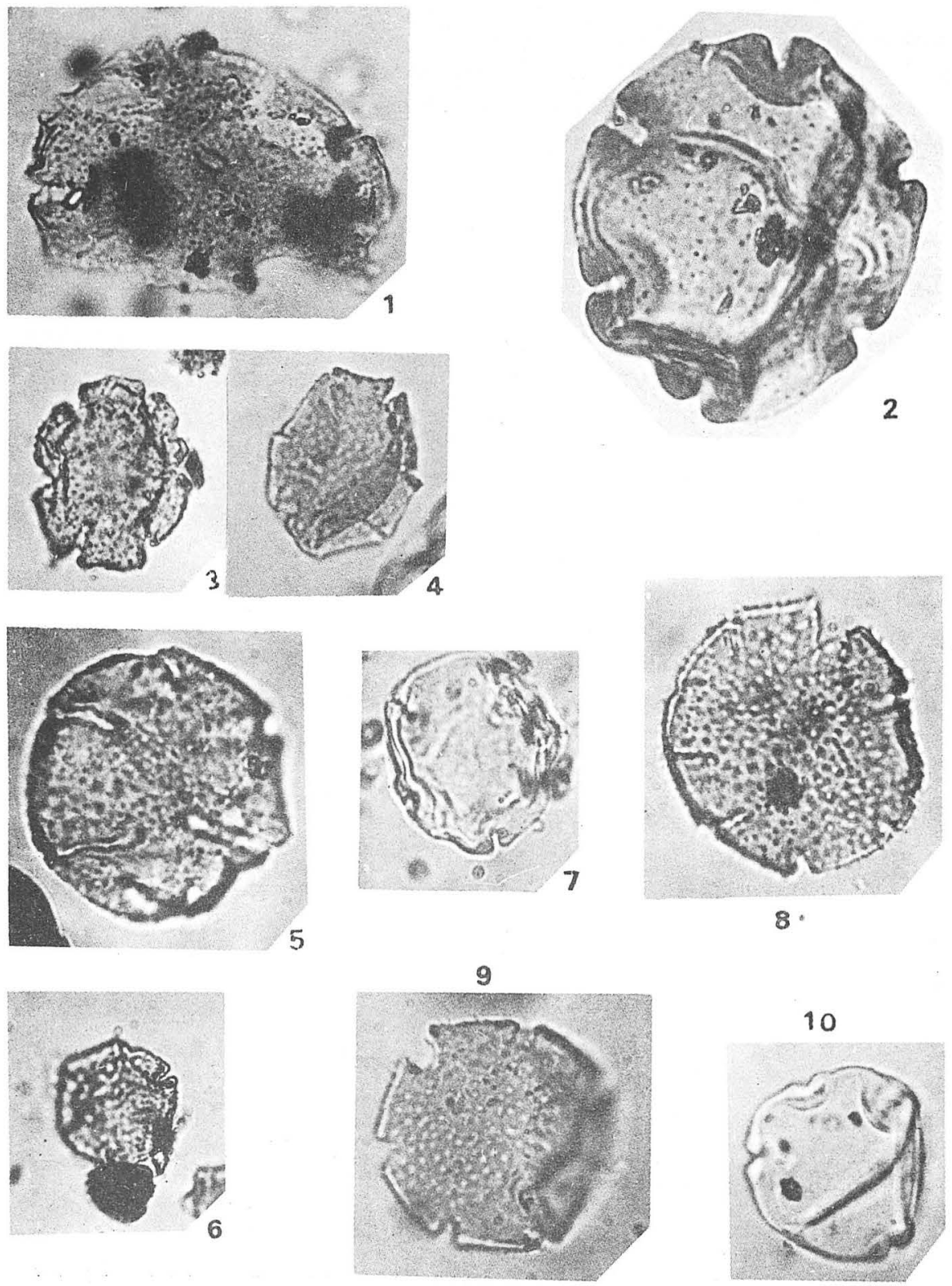

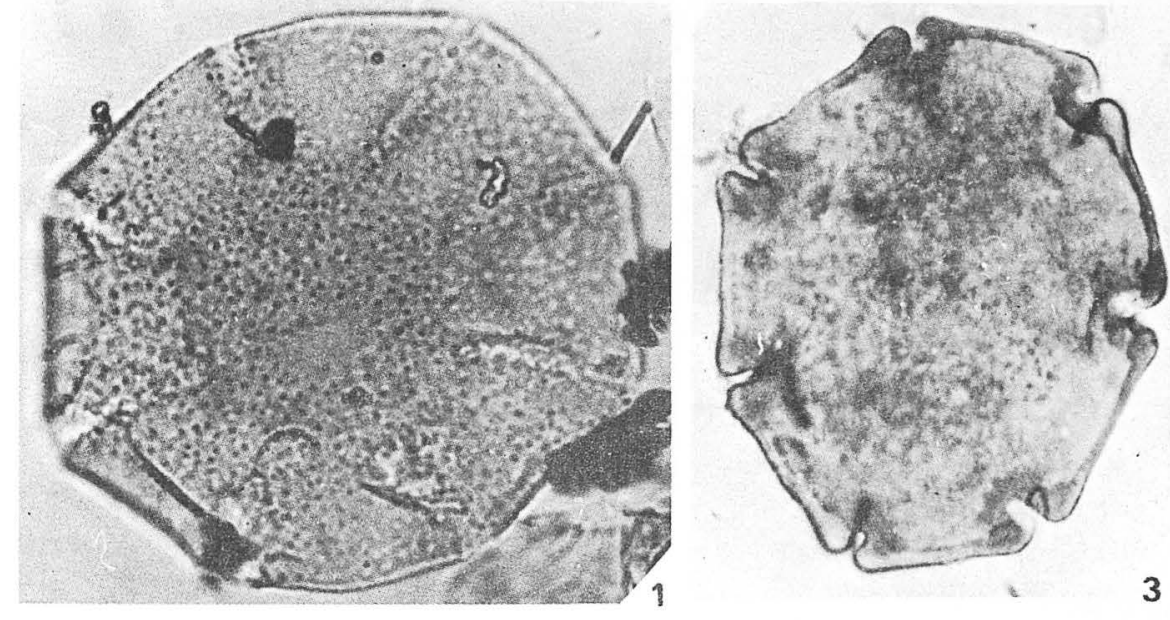
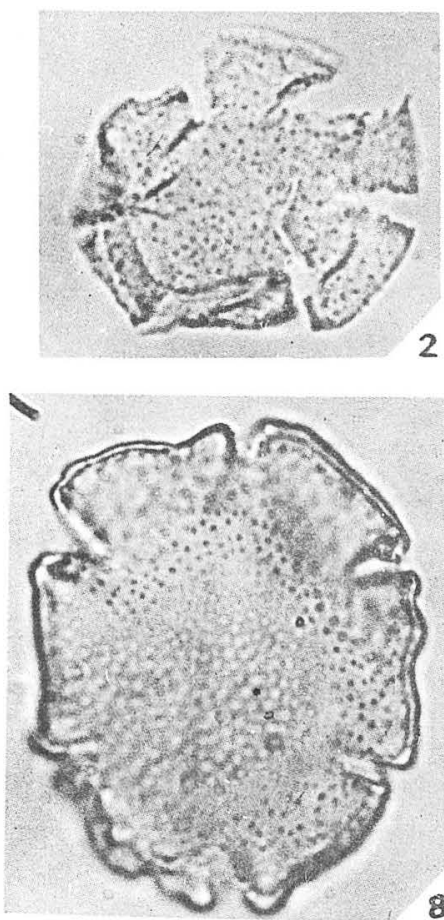

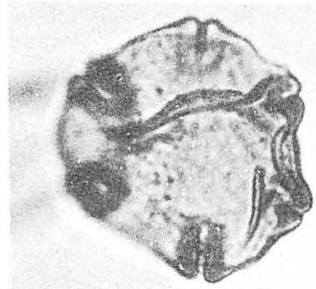

45

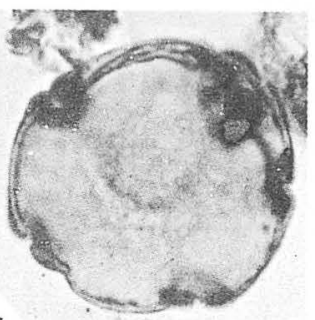

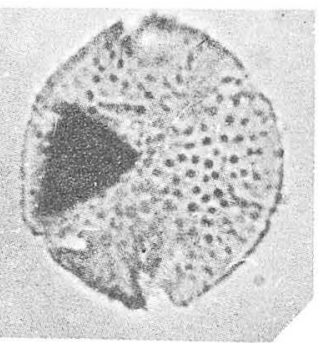

6

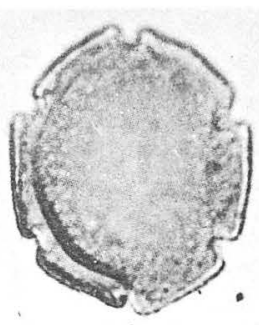

7 